ISBN 978-93-84468-92-7

International Conference on Issues in Education, Literature, Humanities and Social Sciences

(IELHSS-2017)

Kuala Lumpur (Malaysia) Jan. 4-5, 2017

\title{
The Influence of Social Capital on Rural Health Sector: Case Study of households in Ruwanwella Division in Kegalle District of Sri Lanka
}

\author{
Verangika Upananda \\ Faculty of Graduate Studies, University of Colombo, Sri Lanka
}

\begin{abstract}
Despite the common belief that social capital is associated with health wellbeing, this paper addresses the research question, 'does social capital has an association with the health behavior of rural population '. This study was conducted in a Grama Niladhari Division (smallest administrative unit) in Ruwanwella division in Kegalle district, Sri Lanka. To measure social capital, we adopted three commonly accepted dimensions that are at individual level: social participation, social network and trust and reciprocity. The broad term health is used in this study to mean any behavior that may affect individual's physical, mental and self - perceived health. The data were collected through a five point Likert scale questionnaire. The Cronbach alpha value was obtained, which is 0.63. This value vouched for the reliability of the questionnaire. Pearson $R$ was found for each dependent and independent variables and they appeared to have weak correlation with each variable. This study found that association with social participation and physical health and mental health is positive while other two dimension of social capital: social network and trust \& reciprocity has weak relationship with self-perceived heath, mental health and physical health. According to data analysis social network and trust and reciprocity has no impact on self-perceived health, physical and mental health in rural areas in the country despite the traditional belief of that these factors play a major role in determining health of rural communities Considering the higher unemployment rate (55.9\%) and low educational level, these results suggest that health may more associated demographic factors than social capital.
\end{abstract}

Keywords: Social capital, social participation, social network, trust and reciprocity, self-perceived health, physical and mental health, rural health sector.

\section{Introduction}

There has been increased interest in social capital in the field of health. The concept of social capital is not restricted to any specific definition of health but has been linked with numerous health outcomes. The concept of social capital has also been linked with various health-related behaviors such as smoking, physical activity, dietary habits and prevalence of various diseases. Social Capital as defined by Woolcock (1999) is "It's not what you know, it's who you know." Then it is important to understand how social capital influences directly or through health behavior which will mitigate the expenditure of health care service of a country. Moreover, such an exploration may help developing policies for the well-being of the poorest section of the population.

Social capital has extensively been discussed among scholars. However, it is an inadequately discussed concept locally. In this study, social capital is defined operationally as the total stock of social relationships that an Individual possesses. It is assumed that health behavior acts as a mediator between social capital and health. The general aim of this paper is to shed light on social capital as a determinant of health in rural sector of the country.

\subsection{Problem background}

As defined by WHO, health behavior is not confined free of diseases or infirmity but includes physical, social and mental well-being. Since social and mental well-being is an abstract concept as well as social capital, it is 
necessary to understand how these abstract concepts interact with each other. Generally, health cannot be attained without social and mental well-being. As a result, people seek the assistance of free healthcare service. Then, considerable proportion resources may mobilize which could have been prevented by improved social capital.

\subsection{Research objective}

The general objective of the study was to examine the association between social capital and health among, the adult population in two villages named 'Mahalla' and 'Devek Kanda' in Kegalle district in Sabaragamuwa Province.

\section{To examine the relationship between social capital and health, indicated by self-rated health and mental health and physical health.}

\subsection{Study location}

The selected location is 'Malhalla' a Grama Niladhari Division, No 104. It is located in Ruwanwella Divison (DS) secretariat in Kegalla District, Sabaragamuwa Province, bordering Kelani River, one of the four major rivers in Sri Lanka. The population, according to the census and statistic department of 2014 is 824,862 in the district. There are 11 Divisional Secretariat in Kegalle district. Ruwanwella is one of them. There are 38 Grama Niladhari divisions in Ruwanwella, which comprised of 136 villages. The selected Mahalla Grama Niladhari Division consists with two villages and two estates with the total population of 2170 . This study is carried out in two villages, Mahalla and Devek Kanda. The majority of the population earns their livelihood by working in rubber plantations. People live close to the river to earn their living by mining sand which replenishes after every flood which is also a major problem of the area. The territory of Kegalle comprises of $48 \mathrm{~km}$ from North to South and 32 $\mathrm{km}$ from East to West and marks of its extent as $1663 \mathrm{~km}^{2}$.

\section{Literature review}

\subsection{Social capital}

The term social capital defines on social structures and social networks which are characterized by norms of trust and reciprocity. The social capital emerged as an insignificant domain in 1916 and grown into major domain since 1970 due to seminal work of Granovetter (1973) who introduce weak ties and strong ties in social networks, Burt (1992) and Forte (1993), who describe social capital as doubled-edged sword. On the one hand, it facilitates access to valuable community service while it is having economic cost for engaging in no-economic gain activities of the community. According to Forte, social capital has two dimensions. Weak ties or extra -community ties which bridges people and the strong ties which bond people together by friendships and blood relationships termed intra-community ties. Bonding social capital is characterized by network density, which termed to identify the number of connections per person in the network. However, these dimensions dynamic and change over time as individual, acquire more or fewer resources. Weak ties could be stronger as one gets higher position in the network while strong ties could be weakened as one changes the his or her demographic location or connected to a another network. For example, when one marries he may connected to a another network and that network may stronger than the former bonding tie. As a result, strong ties become weakened.

However, after 1980's due to the publications of Pierre Bourdieu, Robert Putnam and James Coleman, the concept of Social Capital has become better known concept, particularly in disciplines like sociology and economics. These scholars define Social Capital in different ways. According to Bourdieu, "Social capital is the aggregate of the actual or potential resources which are linked to possession of a durable network of more or less institutionalized relationships of mutual acquaintance and recognition - or in other words, to membership in a group - which provides each of its members with the backing of the collectivity-owned capital, a 'credential' which entitles them to credit, in the various senses of the word." The American scholar Coleman defines social capital by its function. "It is not a single entity but a variety of different entities, with two elements in common: they all consist of some aspect of social structures, and they facilitate certain actions of actors - whether persons or corporate actors - within the structure" Robert Putnam considered the society with high level of social participation, trust and reciprocity as a base of mutual benefit that leads to higher social interaction among people. 
As per literature, there are two level of social capital: Collective property and individual property. The collective property of social capital began to be popular with the views of Bourdieu, Putnam and Coleman. The study is based on first level of social capital considering it as collective property.

\subsection{Health}

According to World Bank (1946) definition, health well being has three dimensions: Free of diseases of physical health, mental health, social well-being (societal helath). Many studies has carried out to research the link between social capital and health. During recent past association between health and social capital has gained noticeable attention after the work of Ichiro Kawachi. They mainly found the associations between mortality and community relationships. Since then number of work on social capital and health has increased. The health related research is often repleted with income inequality, poverty and policies related to these area. Later, the associations among these factors has turned to a fresh direction, the health and its association between soceity. Some of the studies such as Corelation among, income inequality, social capital and mortility, (Kawachi, Kennedy, Lochner, at el, 1998), Potential role of social capital and civic soeity on health, (Kawachi, Lochner, 1997) have given an insight to the relationship between social capital and health. Kawachi and his collegues (1998) found that socail capital and cohesion indicators were associated with aged-adjusted mortality and life expectancy .

Self perveived health is the valid measure of overall health. Rose (2000) found that human capital and social capital are associated strongly with self perceived health and strong mental health. Veenstra (2000) performed a stduy to determine if there is a relationship between self rated health and trust, civic norms, social particiation and social engagement. He found evidence that several measures of social engagment and social participation are strongly associated with self rated health. According to his study, civic norms and trust were not corelated with self rated heath.

McCulloch (2001) was one of the first to reseach the relationship between social capital and mental health. He suggested that people with low level of social capital and neighboohood have higher level of risk of psychiatric morbidity. A survey carried out in Australia (2006) found the evidence of that trust and feeling safe and reciprocity were having lower risk of mental health. Another multilevel study in Japan found that trust, known as cognative social capital were associated with indivisual menatal health.

Health beahviors and physical health are generally associated with socio-demografic factors. Makenbach JP(2008) at el, Crosby RA at el (2003), Weitsman (2004) at el , Linstrom LM, (2011) and Linstrom M, Moghaddassi M, at el (2003) found evidence in their studies that sexual risk behavior, number of ciggerett smoking, less physical activity contributed to the low level of social participation.

Inspite of increasing number of studies on Social capital and heath, the comparability is indirect due to difficulty in measuring the variables of social capital. This study forms an association between different dimensions of social capital and helth, which enable better understanding of the association of these dimensions.

\section{Method}

\subsection{Population and Sampling}

The population of the study selected from the government website of Kagalle divisional Secretariat taken in 2016 which is the sampling frame for this study. The cluster sampling is the selected as sampling methodology. The two villages namely, Dewek Kanda, (total population is 705) and Mahalla (total population is 676). The population of the study is adults over 16 years of age lived in these two villages at least more than one year. The sample includes 111 individuals, 59 and 52 from Devek Kanda and Mahalla respectively.

\subsection{Survey instrument}

A five point liker scale questionnaire is developed to collect data, which consisted of three parts, namely demographic factors, social capital and health behavior and health. Reliability analysis of the questionnaire was done through calculation of Cronbach alpha value and it was found 0.63 which is above 0.6. This indicates the questionnaire is reliable and serves the purpose of the research. 


\subsection{Operationalization}

As the concept of social capital is multidimensional phenomenon, there are large variety of dimensions and methods of measuring social capital. This study measured social capital at individual level in three popular dimensions of social capital a namely social participation, social network and trust and reciprocity. Social participation is a collective action. It enables individuals to access resources that would not be available otherwise. Social networks are ties between individuals and groups and characterized as bonding, bridging and linking. Trust is important to establish interpersonal relationships. Reciprocity is willingness to help other expecting their support in future. The study has chosen social trust as reciprocity as one of the dimensions of social trust.

The health and health behavior is the independent variables measured in terms of self-perceived health, physical health and mental health. The following Table illustrates the how this study translates abstract concepts into measurable terms.

TABLE I: Dimensions of health behavior and social capital

\begin{tabular}{|l|l|l|}
\hline \multicolumn{1}{|c|}{ Concept } & \multicolumn{1}{|c|}{ Variables } & \multicolumn{1}{c|}{ Indicators } \\
\hline Social Capital & Dependent Variables & \multicolumn{1}{|c|}{$\begin{array}{l}\text {-Talking over the telephone with friends \& family } \\
\text {-Spending leisure time with friends \& family } \\
\text {-Visiting friends \& relatives }\end{array}$} \\
\hline & Social Participation & $\begin{array}{l}\text {-Informal social network Ex. Colleagues at work place } \\
\text {-Borrowing tools and equipment from neighbors \& } \\
\text { friends } \\
\text {-Voluntary participation in community work }\end{array}$ \\
\hline & Trust and reciprocity & $\begin{array}{l}\text {-Trusting neighbors } \\
\text {-Feeling of security \& protection to live in the } \\
\text { neighbors. } \\
\text {-Reciprocity }\end{array}$ \\
\hline Health & Independent Variables & $\begin{array}{l}\text {-Feeling of happiness } \\
\text {-Feeling of healthiness } \\
\text {-Feeling of contentment and satisfaction }\end{array}$ \\
\hline & Self-perceived health & $\begin{array}{l}\text {-Feeling of being a part of everyday activities } \\
\text {-Feeling of suicidal } \\
\text {-Adequate number of sleep }\end{array}$ \\
\hline & Mental health & $\begin{array}{l}\text {-Active physical activities } \\
\text {-Consumption of alcohol } \\
\text {-Smoking }\end{array}$ \\
\hline & Physical Health &
\end{tabular}

\subsection{Hypothesis}

There are 3 hypothesis built to elaborate the relationship between variables and to determine whether there is an association between independent and dependent variables.

H1: Social Network has a positive impact on self-perceived health, mental health and physical health.

H2: Social Participation has a positive impact on self-perceived health, mental health and physical health.

H3: Trust and Reciprocity has a positive impact on self-perceived health, mental health and physical health.

\subsection{Method of data Analysis}

Univariate and Bivariate Analysis

The statistical software package, version 20 was used to analyze data. Demographic information of respondents was measured through frequency distribution. To identify the relationship between variables of Social capital and health, the statistical technique of Correlation Coefficient Analysis (Pearson R) and Multiple Linear Regression model were used. 


\section{Results and Analysis}

\subsection{Demographic Factors}

$67.6 \%$ of the respondents were female and $32.4 \%$ is male in the selected sample. The mean value of the respondents is $41.78 .4 \%$ of the respondents are married, $13.5 \%$ are single and balance of $8.1 \%$ is widowed. The employment of the respondents are categorized in six sections, namely Unemployed, Self-employed, estate laborer, Private sector, public sector and retired. 55.9\% of the respondents are unemployed, $14.4 \%$ works in private sector and $11.7 \%$ are self-employed. The education level of respondents were measured in seven categories, namely up to grade 5, up to grade 11, GCE (OL) passed, up to GCE (A/L), GCE (A/L) passed, Graduate and vocational training. The majority of the sample $41.4 \%$ was studied up to GCE $(\mathrm{O} / \mathrm{L}) .21 .6 \%$ of respondents have passed GCE $(\mathrm{O} / \mathrm{L})$ and $11.7 \%$ were only studies up to grade five. The mean value of the residency of this area is $19.6 \%$, which is nearly 20 years.

\subsection{Summary of the relationship between independent variables and dependent variables}

Pearson R showed a weak correlation among dependent and independent variables

TABLE II: Summery Of the Relationships of Variables

\begin{tabular}{|l|l|}
\hline Variable & Relationship \\
\hline Social Participation & Weak correlation with all 3 independent variables \\
\hline Social Network & Weak correlation with all 3 independent variables \\
\hline Trust \& reciprocity & Weak correlation with all 3 independent variables \\
\hline
\end{tabular}

\subsection{Results of Multiple Linear Regression Analysis}

$\mathrm{P}$ value of Social participation and independent variables is 0.003 .

$\mathrm{P}$ value of Social network and independent variables is 0.398

$\mathrm{P}$ value of trust and reciprocity and independent variable is 0.568

As such, $\mathrm{H} 1$ is accepted. $\mathrm{H} 2$ and $\mathrm{H} 3$ are rejected.

\section{Conclusion}

The analysis provide evidence that dimensions of social capital: social network and trust and reciprocity are weakly associated with self -perceived health, physical health and mental health and the social participation, another dimension of social capital has positive association with self -perceived health, physical and mental health. Finally, the results may not be generalizable to all rural Sri Lankans. In particular, this study under-represent employed population in the selected sample who were not at homes during the data collection. This missed category of people tends to be male and income earners.

The aforesaid limitation notwithstanding, this study provides the base on which future research in effect of social capital and health in rural Sri Lankans can be built on.

\section{Acknowledgements}

The author is grateful to Professor K. Amirathalingam, and Dr. Ruwan Jayathilake at Department of Economics, University of Colombo for their valuable comments to develop this paper.

\section{Reference}

[1] Coleman, J. S. (1988). Social Capital in the Creation of Human Capital. American Journal of Sociology, 94. doi: $10.1086 / 228943$

[2] Ferlander, S. (2007). The Importance of Different Forms of Social Capital for Health. Acta Sociologica, 50(2), 115-128. doi:10.1177/0001699307077654

[3] Harpham, T. (2002). Measuring social capital within health surveys: Key issues. Health Policy and Planning, 17(1), 106111. doi:10.1093/heapol/17.1.106 
[4] Kawachi, I., Kennedy, B. P., \& Glass, R. (1999). Social capital and self-rated health: A contextual analysis. Am J Public Health American Journal of Public Health, 89(8), 1187-1193. doi:10.2105/ajph.89.8.1187

[5] Lomas, J. (1998). Social capital and health: Implications for public health and epidemiology. Social Science \& Medicine, 47(9), 1181-1188. doi:10.1016/s0277-9536(98)00190-7

[6] Macinko, J., \& Starfield, B. (2001). The Utility of Social Capital in Research on Health Determinants. The Milbank Quarterly Milbank Quarterly, 79(3), 387-427. doi:10.1111/1468-0009.00213

[7] Sutton, S. (n.d.). Determinants of Health-Related Behaviours: Theoretical and Methodological Issues. The SAGE Handbook of Health Psychology, 94-126. doi:10.4135/9781848608153.n4

[8] Szreter, S. (2004). Health by association? Social capital, social theory, and the political economy of public health. International Journal of Epidemiology, 33(4), 650-667. doi:10.1093/ije/dyh013

[9] Yip, W., Subramanian, S., Mitchell, A. D., Lee, D. T., Wang, J., \& Kawachi, I. (2007). Does social capital enhance health and well-being? Evidence from rural China. Social Science \& Medicine, 64(1), 35-49. doi:10.1016/j.socscimed.2006.08.027

[10]Ziersch, A. M., Baum, F. E., Macdougall, C., \& Putland, C. (2005). Neighbourhood life and social capital: The implications for health. Social Science \& Medicine, 60(1), 71-86. doi:10.1016/j.socscimed.2004.04.027 